\title{
Phylogeny of cultivable heterotrophic bacteria derived from mixed colonies
}

\author{
Patrícia S. Costa, Cláudia I. Lima-Bittencourt, Francisco A. R. Barbosa, \\ Edmar Chartone-Souza, Andréa M. A. Nascimento* \\ Departamento de Biologia Geral, Instituto de Ciências Biológicas, \\ Universidade Federal de Minas Gerais; Av. Antônio Carlos 6627 Belo Horizonte, Minas Gerais, CEP 31270-901, Brazil
}

\begin{abstract}
In nature, bacteria interact with each other in ways that do not occur in pure laboratory cultures. However, when bacteria are purified from environmental samples, the resulting colonies occasionally harbor diverse bacterial isolates, which we have termed 'associated isolates'. Bacteria were obtained from a freshwater lake along a euphotic gradient $(100,10$ and $1 \%$ light penetration). Surprisingly, 76 of the 1196 resulting colonies harbored between 2 and 5 associated isolates (for a total of 168 associated isolates), and 121 of these associated isolates were recovered as pure cultures. A portion of the isolates (47/168) was non-viable after re-streaking, suggesting an inability to survive and reproduce in the absence of their associates. Partial sequencing of $16 \mathrm{~S}$ rDNA revealed that these isolates were affiliated with Proteobacteria, Firmicutes, Bacteroidetes, Actinobacteria and Deinococcus-Thermus, and represented 26 genera. Colonies harboring associated isolates and those that harbored the largest number of isolates were primarily sampled from the $1 \%$ euphotic gradient. Significant differences in the distribution of associated isolates along the euphotic gradient suggest that environmental factors are driving these associations.
\end{abstract}

KEY WORDS: Associated bacteria · Intracolony · Diversity · 16S rDNA · Freshwater

\section{INTRODUCTION}

The current traditional and molecular approaches applied to study microorganisms are based on their isolation from pure clonal cultures or from DNA recovered directly from environmental samples of both cultivable and not cultivable organisms. By isolating microorganisms from their communities, it is possible to focus on their behavior in biologically simple environments such as Petri dishes and test tubes, while ignoring the complex network of interactions that occur in their natural environments. Indeed, microbial communities are dynamic consortia, interacting with other microorganisms and other forms of life (Shapiro \& Dworkin 1997, Rudi et al. 2007, Little et al. 2008).
Although it is known that bacterial communities contain many different organisms that may grow together in culture, pure cultures are primarily used to study the physiological and genetic features of a specific type of bacteria. Traditionally, the culturebased approach has been employed as a first attempt to understand the properties and functioning of a bacterial community. However, an additional analysis describing intracolony bacterial associations from a natural community has not been addressed.

As part of an ongoing effort to investigate bacterial taxa from natural environments, we have used restreaking from an isolated colony as a strategy for obtaining pure cultures. However, over the years we have noticed that ascertaining the purity of a culture is not always easy, and it is often necessary to go 
through several stages of re-streaking to obtain pure cultures. Moreover, in many cases, when the physical separation of associated isolates is accomplished, one or all of them does not survive, suggesting their physiological inability to survive and reproduce in the absence of certain associations. The objective of this study was to provide insight into the phylogeny of isolates derived from an original colony. We looked for the presence of 2 or more different taxa from a single colony, performing a molecular and phylogenetic characterization of these isolates. These bacteria were collected from a natural freshwater lake in a tropical region.

\section{MATERIALS AND METHODS}

\section{Study area and sampling site}

Carioca Lake is a natural body of water situated in the middle of the Rio Doce Basin of Brazil. It is located in a Conservation Unit (Parque Estadual do Rio Doce, PERD, $19^{\circ} 29^{\prime} 24^{\prime \prime}$ to $19^{\circ} 48^{\prime} 18^{\prime \prime} \mathrm{S}$ and $42^{\circ} 28^{\prime} 18^{\prime \prime}$ to $42^{\circ} 38^{\prime} 30^{\prime \prime} \mathrm{W}$ ) that is the largest remnant of Atlantic Forest in the state of Minas Gerais. Carioca Lake is mesotrophic, round, shallow (11.8 $\mathrm{m}$ of maximum depth) and relatively small, with an area of 14.1 ha (Bortoluzzi et al. 2004, Bezerra-Neto et al. 2010).

\section{Sampling and bacterial isolation}

Water samples $(500 \mathrm{ml})$ across a euphotic gradient in the limnetic (Lim) zone (Carioca Lake) were taken with Van Dorn bottles. The same water samples were used for physical and chemical measurements and bacterial culture. Collections took place on 23 June and 27 August 2007, which is the dry season. Sampling was conducted in the water column at different degrees of light penetration $(100,10$ and $1 \%)$, as determined by Secchi disk. To assess water conditions, selected physical and chemical variables were measured at 3 points in the euphotic gradient. Water temperature, $\mathrm{pH}$ and dissolved oxygen (DO) concentration were measured in situ with a multiprobe (Horiba, model U-22) (Mackereth et al. 1978). Concentrations of total nitrogen (TN), total phosphorus (TP), ammonium $\left(\mathrm{NH}_{4}{ }^{+}-\mathrm{N}\right)$, nitrite $\left(\mathrm{NO}_{2}-\mathrm{N}\right)$, nitrate $\left(\mathrm{NO}_{3}-\mathrm{N}\right)$, and soluble reactive phosphorus $\left(\mathrm{PO}_{4}-\mathrm{P}\right)$ were measured as previously described (Golterman et al. 1978, Mackereth et al. 1978).

Bacteria were isolated by plating $100 \mu \mathrm{l}$ of water sample directly (and with serial dilution) on Peptone- tryptic-yeast extract glucose (PTYG) agar plates (Brown \& Balkwill 2009), which were then incubated at $28^{\circ} \mathrm{C}$ for up to $7 \mathrm{~d}$. The PTYG medium was chosen to allow an overall growth of the culturable aquatic bacteria with different nutritional demands. The resulting colonies were re-suspended in saline $(0.85 \%, \mathrm{w} / \mathrm{v})$, vortexed and repeatedly streaked on the same medium to accomplish their purification. It should be noted that the number of colonies grown on the plates was relatively low (20 colonies), avoiding physical contact during plating. Vortexing was applied to separate randomly stuck cells before each streaking. Isolates derived from a single original colony that harbored isolates with visually different colony morphologies (size, shape, surface, color, texture and elevation) were named 'associated isolates' and were chosen for subsequent molecular analysis. The isolates in this study were named according to the specific euphotic gradient from which they were retrieved (Lim1, Lim10 or Lim100). Moreover, to facilitate the recognition of associations, isolates derived from a single colony were designated by the same number followed by different letters, e.g. Lim1-01A and Lim1-01B.

Statistical analyses were performed with STATISTICA data analysis software, version 7 (StatSoft). Pearson's correlation coefficient was used to test differences between associated isolates and environmental variables. A p-value $\leq 0.05$ was considered to be statistically significant.

\section{DNA extraction and 16S rRNA gene amplification}

Genomic DNA was prepared from a loopful of cells grown in nutrient broth for $18 \mathrm{~h}$ at $28^{\circ} \mathrm{C}$. The cell pellet was re-suspended in $500 \mu \mathrm{l}$ of TE buffer $(0.1 \mathrm{~mol}$ $\mathrm{l}^{-1}$ Tris- $\mathrm{HCl} \mathrm{pH} 8 ; 0.001 \mathrm{~mol} \mathrm{l}^{-1}$ EDTA). The cells were lysed by addition of $30 \mu \mathrm{l}$ of sodium dodecyl sulfate (SDS) $20 \%$ and $3 \mu$ l of Proteinase K (20 $\mathrm{mg} \mathrm{ml}^{-1}$; Invitrogen). The DNA was purified as previously described by Dramsi et al. (1995). The complete 16S rRNA gene was amplified by touchdown PCR according to Pontes et al. (2009), using the conserved primer set PA $\left(5^{\prime}\right.$-TCC TGG CTC AGA TTG AAC GC-3'), modified from Kuske et al. (1997), and U2 (5' ATC GGY TAC CTT GTT ACG ACT TC-3'), described by Lu et al. (2000).

\section{Amplified ribosomal DNA restriction analysis}

Amplified ribosomal DNA restriction analysis (ARDRA) was performed to minimize the sequencing 
of isolates. The 16S rDNA was amplified with primers PA and U2 and then digested separately (according to the supplier's recommendations) with 2 restriction enzymes (NlaIV and AflIII; New England Biolabs) that recognize sequences of 6 nucleotides. Digested DNA was separated in $2 \%$ agarose gels in Trisacetate-EDTA (TAE) buffer. After electrophoresis at $75 \mathrm{~V}$ for $2.5 \mathrm{~h}$, the gels were recorded and photographed. One to 3 isolates per ARDRA pattern were subsequently sequenced.

\section{Genomic fingerprinting}

Repetitive extragenic palindromic (rep)-PCR genomic fingerprinting was performed with all the isolates using the $(\mathrm{GTG})_{5}$ primer and $(\mathrm{GTG})_{5}$-PCR amplification cycling conditions described by Freitas et al. (2008). Products were separated by electrophoresis in $2 \%$ agarose gels in $1 \times$ TAE buffer for $3 \mathrm{~h}$ at $75 \mathrm{~V}$ and visualized by staining with ethidium bromide $\left(0.5 \mathrm{mg} \mathrm{ml}^{-1}\right)$. Fingerprints were analyzed using BioNumerics version 6.0 software (Applied Maths). Digitized gel images were converted and normalized using a $1 \mathrm{~kb}$ Plus DNA Ladder (Invitrogen). Similarity between sets of fingerprint patterns was calculated using the pairwise Pearson's product-moment correlation coefficient $(r$; these values are often represented by percent similarity, where an $r$ of 1 is equivalent to $100 \%$ ). This approach compares the entire densitometric curves of the fingerprints (Häne et al. 1993). Cluster analysis of pairwise similarity values was performed using the UPGMA algorithm.

\section{Sequencing and phylogenetic analysis}

The partial 16S rRNA gene sequence was obtained using the primers PA and E926R ( 5 '-CCG ICI ATT IIT TTI AGT TT-3') (Watanabe et al. 2001). Sequencing reactions were performed with a DYEnamic ET Dye Terminator Kit (GE Healthcare) and a MegaBACE 1000 capillary sequencer (GE Healthcare) according to the manufacturers' instructions. The 16S rRNA gene sequences were analyzed, checked for quality, aligned, and edited to produce a consensus using Phred v.0.20425 (Ewing \& Green 1998), Phrap v.0.990319 (www.phrap.org) and Consed 12.0 (Gordon et al. 1998) software. To determine the approximate phylogenetic affiliations of our 121 isolates, the 16S rRNA gene consensus sequences were aligned to sequences in GenBank using BLASTN and to sequences in the Ribosomal Database Project (RDP) using Classifier search. Phylogenetic relationships were inferred by MEGA 4 (Tamura et al. 2007) using the neighbor-joining method (Saitou \& Nei 1987) and Kimura's 2-P model of sequence evolution. The robustness of the phylogenetic tree topology was evaluated with 1000 replicates of bootstrap analysis. The nucleotide sequences generated were deposited in the GenBank database with accession numbers HQ234363 to HQ234483.

\section{Bacterial community analysis}

The UniFrac metric method (http://bmf.colorado. edu/unifrac) was used to compare bacterial communities from each euphotic gradient using phylogenetic information (Lozupone et al. 2006). The phylogenetic data were used to compare bacterial communities, and statistical differences were tested among all samples by using UPGMA and principal component analysis (PCA).The cluster environments function of UniFrac and PCA were used to determine the bacterial community similarity among euphotic gradients. Jackknifing was used to support UPGMA clustering results, and significance tests were also performed, as previously described (Lozupone \& Knight 2005).

\section{RESULTS}

\section{Abiotic features of the water column}

To relate the associated isolates to physical and chemical features of the water column, measurements of temperature, $\mathrm{pH}, \mathrm{DO}$ and several other chemical variables were made at different points of the euphotic gradient (Table 1). In both samplings, the water column exhibited isothermal conditions. In August, the $\mathrm{pH}$ was close to neutral. The maximum difference in $\mathrm{pH}$ between sampling points along the euphotic gradient (100 to $1 \%$ ) was 1.7 in June, whereas in August this difference was only 0.1. In June, the maximum DO concentration was $9.1 \mathrm{mg} \mathrm{l}^{-1}$ (100\% light penetration) and the difference in DO concentration between the sampling points of the euphotic gradient was 1.8, compared with 1.6 in August.

Inorganic phosphorus and nitrogen are often limiting nutrients in aquatic environments. In Carioca Lake, the N:P ratio was greater than 9, except at 10 
Table 1. Environmental parameters obtained in the water column from Carioca Lake, Brazil, 2007. For parameter definitions, see 'Materials and methods'

\begin{tabular}{|c|c|c|c|c|c|c|}
\hline \multirow{2}{*}{$\frac{\text { Parameter }}{\text { Light penetration }(\%)}$} & \multicolumn{3}{|c|}{-23 June $2007-$} & \multicolumn{3}{|c|}{-27 August $2007-$} \\
\hline & ) 100 & 10 & 1 & 100 & 10 & 1 \\
\hline $\mathrm{pH}$ & 7.3 & 6.3 & 5.6 & 7.4 & 7.7 & 7.3 \\
\hline Temperature $\left({ }^{\circ} \mathrm{C}\right)$ & 23.0 & 22.4 & 22.0 & 23.6 & 23.0 & 21.6 \\
\hline $\mathrm{DO}\left(\mathrm{mg} \mathrm{l}^{-1}\right)$ & 9.1 & 8.7 & 7.3 & 8.4 & 8.3 & 6.8 \\
\hline $\mathrm{TP}\left(\mu \mathrm{g} \mathrm{l}^{-1}\right)$ & 18.06 & 19.09 & 25.64 & 25.38 & 26.76 & 34.62 \\
\hline $\mathrm{TN}\left(\mu \mathrm{g} \mathrm{l}^{-1}\right)$ & 370.90 & 354.70 & 404.50 & 201.35 & 221.55 & 365.55 \\
\hline TN/TP & 20.5 & 18.05 & 15.7 & 7.9 & 8.2 & 10.55 \\
\hline $\mathrm{PO}_{4}{ }^{3-}-\mathrm{P}\left(\mu \mathrm{g} \mathrm{l^{-1 }}\right)$ & 1.22 & 5.87 & 2.20 & 1.87 & - & 3.93 \\
\hline $\mathrm{NH}_{4}^{+}-\mathrm{N}\left(\mu \mathrm{g} \mathrm{l}^{-1}\right)$ & 121.85 & 114.55 & 112.65 & 43.11 & 41.56 & 122.75 \\
\hline $\mathrm{NO}_{3}^{2-}-\mathrm{N}\left(\mu g \mathrm{l}^{-1}\right)$ & 32.23 & 38.48 & 32.17 & 28.54 & 45.31 & 42.14 \\
\hline $\mathrm{NO}_{2}^{2-}-\mathrm{N}\left(\mu \mathrm{gl}^{-1}\right)$ & 1.71 & 2.10 & 1.62 & 1.58 & 2.28 & 1.38 \\
\hline
\end{tabular}

Of the colonies harboring multiple isolates, those with 2 associated isolates predominated (Fig. 1). Interestingly, colonies harboring 2 or 3 associated isolates were scattered across the euphotic gradient, whereas colonies harboring 4 or 5 associated isolates were exclusively from the $1 \%$ light penetration sampling point.

\section{Identity of associated isolates based on 16S rRNA gene sequences}

To avoid sequencing several isolates with identical $16 \mathrm{~S}$ rDNA se-

and $100 \%$ light penetration along the euphotic gradient, in August (Table 1). According to Salas \& Martino (1991), this ratio indicates that phosphorus was the most limiting nutrient. Additionally, according to the Salas \& Martino (1991) model, the lake was classified as mesotrophic for both months.

Statistical analysis was performed to reveal which abiotic variables correlate with bacterial associations derived from a single colony. DO concentration was the only abiotic variable that exhibited a statistically significant negative correlation.

\section{Associated isolates}

The colony-forming unit (CFU) counts on PTYG plates indicated that there were $10^{3}$ cultivable heterotrophic bacteria per $\mathrm{ml}$ of water. No statistically significant difference in CFUs was detected throughout the euphotic gradient in June or August $(\mathrm{p}>$ 0.05). A total of 1196 colonies, uniformly distributed throughout the euphotic gradient, were screened to obtain pure cultures. Seventy-six of 1196 colonies harbored between 2 and 5 isolates with visually different colony morphologies, and a total of 168 isolates were obtained from these colonies. Two or more distinct morphologically isolates derived from a single colony were designated as associated isolates. Forty-seven (derived from 21 colonies) of 168 isolates were unable to grow in a second subculture, leaving 121 isolates for molecular and phylogenetic characterization. Thirty-seven of these also failed to grow later. Most of the isolates that were unable to grow were retrieved from the $1 \%$ light penetration sampling point (30/84 and 25/84 unidentified and identified isolates, respectively), followed by $10 \%(12 / 84$ and $9 / 84)$ and $100 \%(5 / 84$ and 3/84). quences, amplicons were digested separately with 2 restriction endonucleases (NlaIV and AflIII) and grouped into different ARDRA patterns. A total of 88 distinct patterns were generated, of which 73 were unique (i.e. found only once in this study). We then sequenced the 16S rRNA gene fragments (490 bp) of these isolates to determine their identities. Phylogenetic analyses of these sequences revealed that the isolates represented a wide diversity of both grampositive and gram-negative heterotrophic bacteria. Representatives of 5 phyla were identified: Proteobacteria, Firmicutes, Actinobacteria, Bacteroidetes and Deinococcus-Thermus (Figs. 2 to 4).

Within these phyla, we identified a variety of genera (Table 2). Phylogenetic analysis of the isolates revealed a predominance of Gammaproteobacteria $(39.1 \%)$ belonging to 9 genera: Enterobacter (13.3\%), Aeromonas (10\%), Acinetobacter (6.6\%), Brevundimonas (3.3\%), Pseudomonas (3.3\%), Rahnella (2.5\%), Moraxella (2.5\%), Burkholderia (1.6\%)

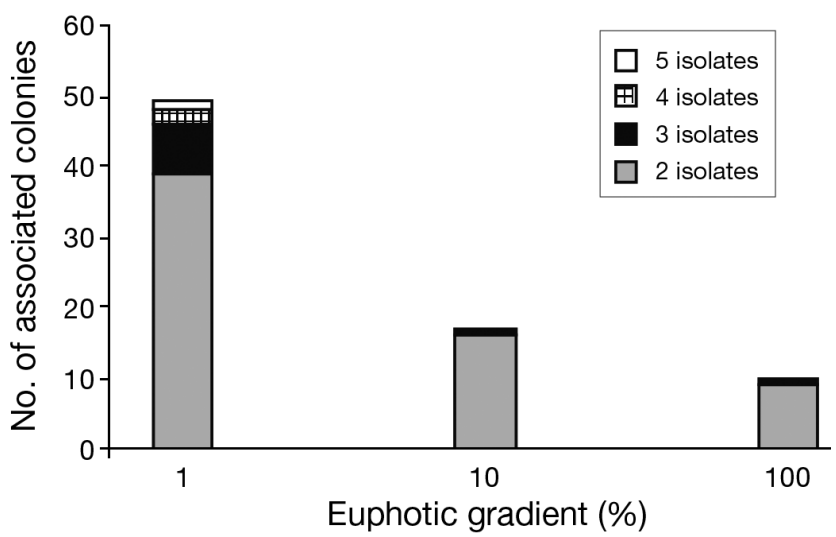

Fig. 1. Number of associated isolates in bacterial colonies sampled at 1, 10 and $100 \%$ light penetration along a euphotic gradient at Carioca Lake, Brazil 


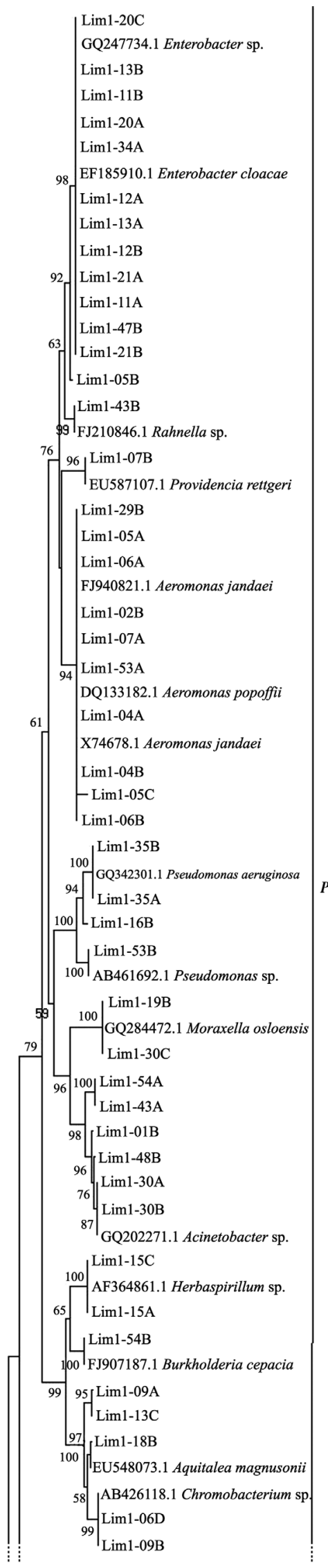

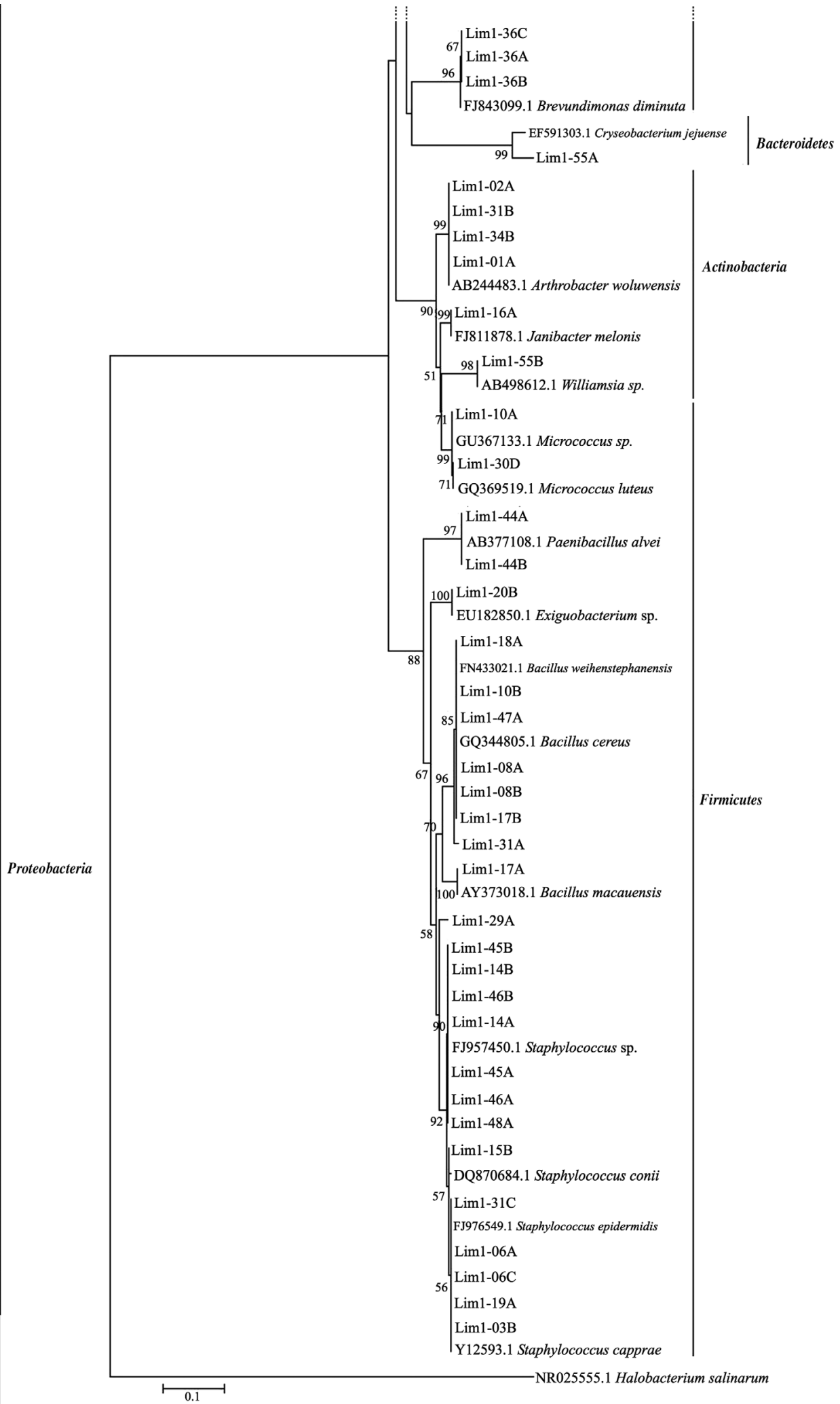

Fig. 2. Phylogenetic tree of isolates from the $1 \%$ light penetration euphotic gradient, based on 16S rRNA gene sequences. The tree was constructed using the neighbor-joining method, and genetic distances were computed by using Kimura's model. Numbers at nodes indicate percentages of occurrence in 1000 bootstrapped trees. Scale bar: 0.1 substitutions per site 
Fig. 3. Phylogenetic tree of isolates from the $10 \%$ euphotic gradient, based on 16S rRNA gene sequences. The tree was constructed using the neighbor-joining method, and genetic distances were computed by using Kimura's model. Numbers at nodes indicate percentages of occurrence in 1000 bootstrapped trees. Scale bar: 0.1 substitutions per site

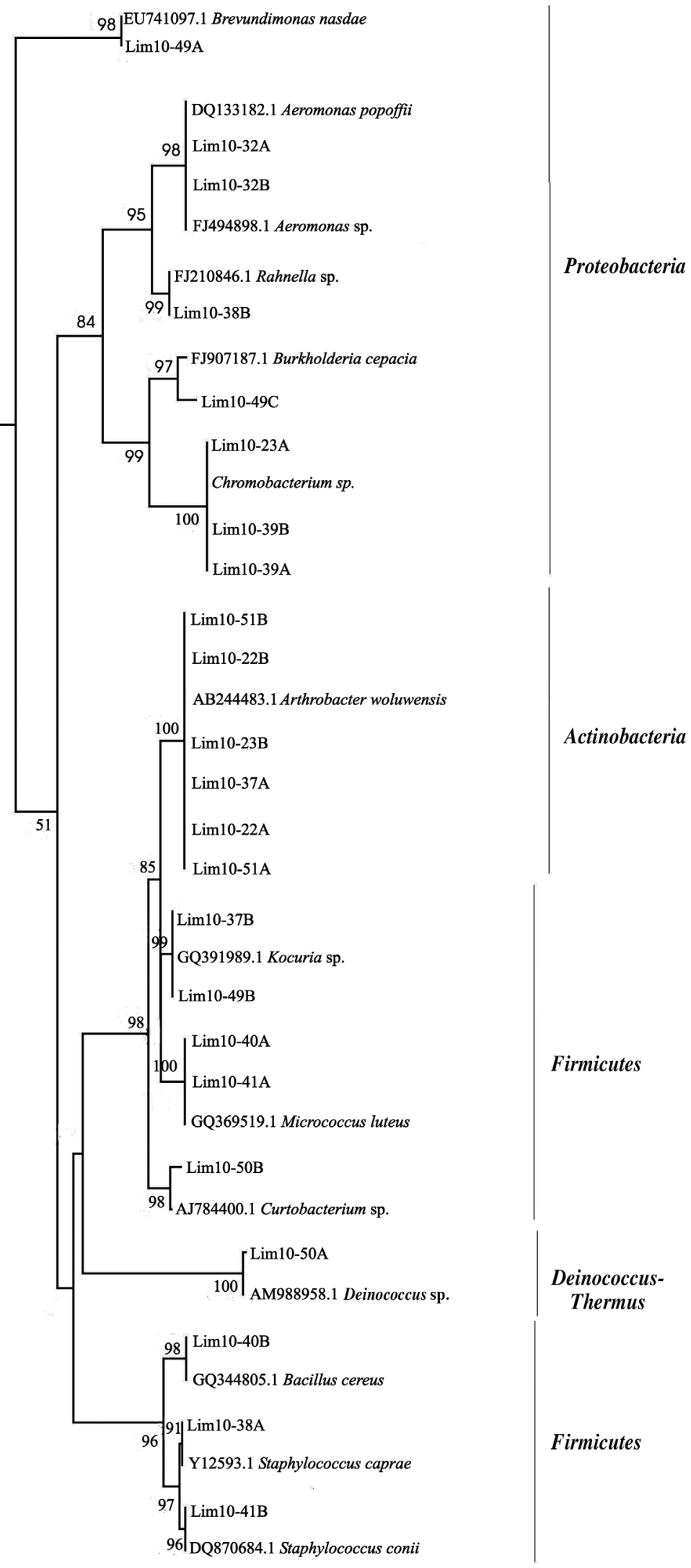


and Providencia $(0.83 \%)$. A great diversity was also found in Firmicutes, with representatives of the following genera: Staphylococcus $(15 \%)$, Bacillus (9.1\%), Micrococcus (3.3\%), Paenibacillus $(1.6 \%)$, Exiguobacterium (1.6\%), Kocuria $(1.6 \%)$, Microbacterium $(0.83 \%)$ and Brevibacillus $(0.83 \%)$. The other isolates were represented by the genera Chromo- bacterium (5.8\%), Herbaspirillum $(1.6 \%)$ and Aquitalea (0.83\%) (Betaproteobacteria); Chryseobacterium (1.6\%) (Bacteroidetes); and Arthrobacter $(9.1 \%)$, Janibacter $(0.83 \%)$, Curtobacterium $(0.83 \%)$ and Williamsia $(0.83 \%)$ (Actinobacteria). The genera Aquitalea, Providencia, Brevibacillus, Deinococcus, Microbacterium, Janibacter, Curtobacterium and
Fig. 4. Phylogenetic tree of isolates from the $100 \%$ euphotic gradient, based on 16S rRNA gene sequences. The tree was constructed using the neighbor-joining method, and genetic distances were computed by using Kimura's model. Numbers at nodes indicate percentages of occurrence in 1000 bootstrapped trees. Scale bar: 0.1 substitutions per site

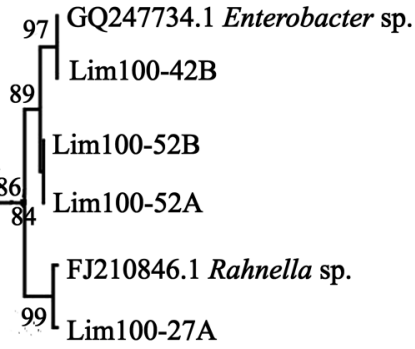

99 $\left.{ }^{83}\right|_{\text {Lim } 100-26 \mathrm{~A}} ^{\mathrm{GQ} 202271.1 \text { Acinetobacter } \mathrm{sp} .}$ Bacteroidetes
Proteobacteria Actinobacteria

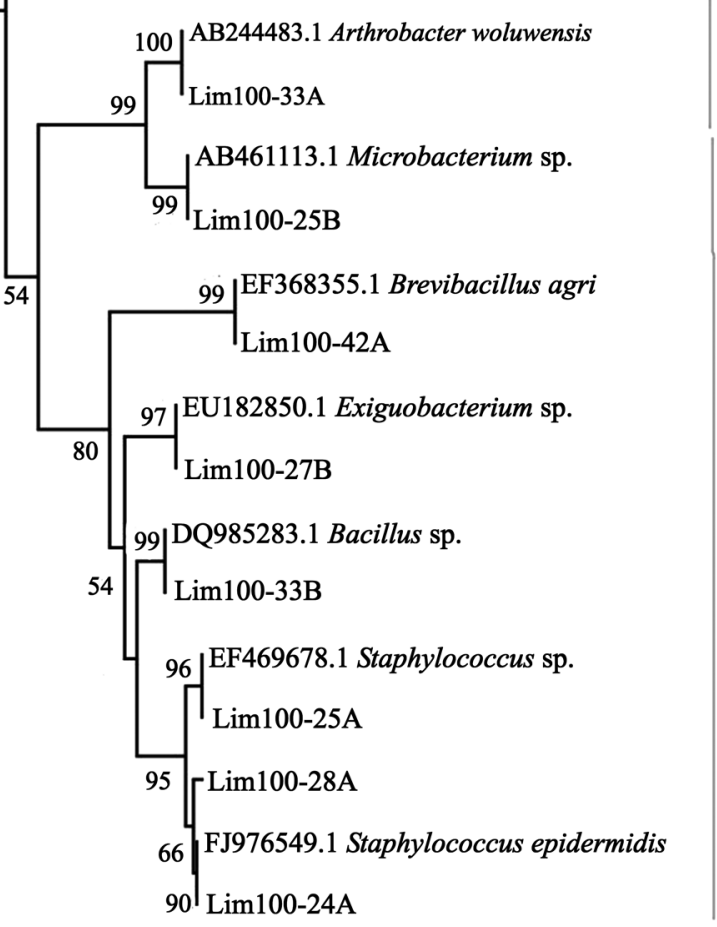

Firmicutes 


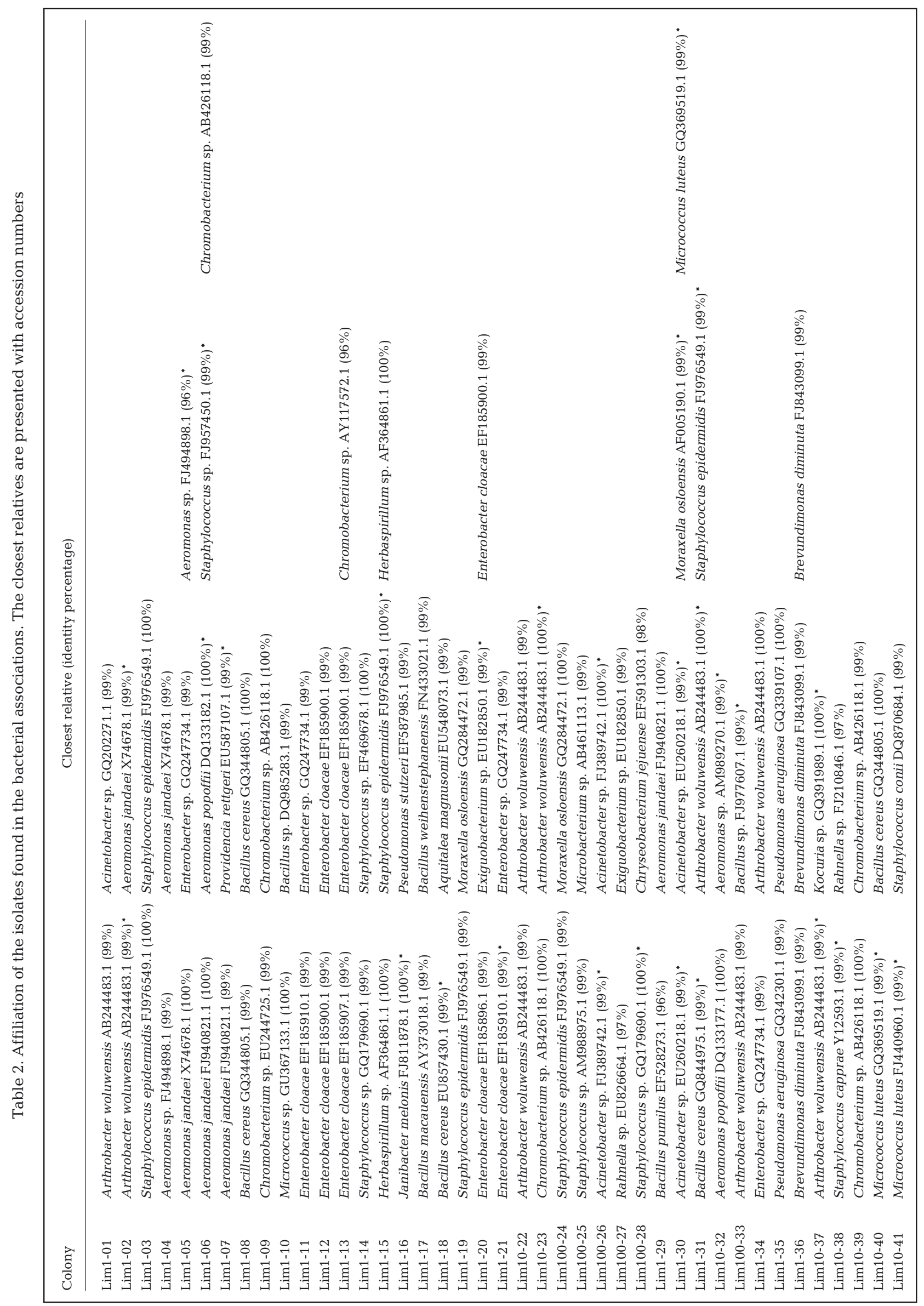




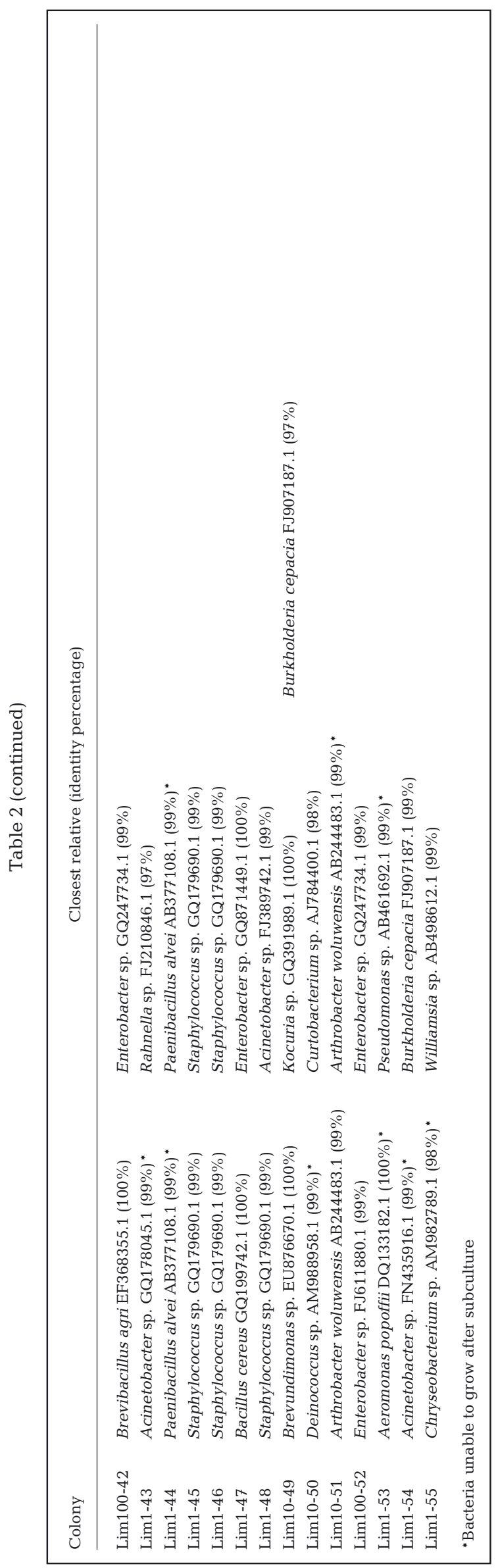

Williamsia were each represented by only one isolate. Of the 26 identified genera, Staphylococcus, Enterobacter and Aeromonas constituted $38.3 \%$ of the isolates.

Of the 55 colonies studied, 42 exhibited unique combinations of associations. Associations that were detected more than once were between members of the same genus (Enterobacter, Lim1-12 and Lim1-13; Arthrobacter, Lim1-22 and Lim10-51; Chromobacterium, Lim1-09 and Lim10-39; and Staphylococcus Lim1-14, Lim1-45 and Lim1-46) and members of different genera (Staphylococcus and Moraxella, Lim119 and Lim100-24) (Table 2).

Eleven of the 26 genera identified were found associated with species within their genus as well as species from other genera (Table 2): Staphylococcus, Brevundimonas Aeromonas, Arthrobacter, Bacillus, Chromobacterium, Enterobacter, Herbaspirillum, Acinetobacter, Pseudomonas and Paenibacillus alvei (the only organism found in association only with itself). We also found associations between 3 different genera that belonged to different phyla (Lim1-06, Lim1-31 and Lim10-49; Table 2). Proteobacteria and Proteobacteria (17/55) was the most common association, followed by Proteobacteria and Firmicutes (12/55). Associations between different phyla (Deinococcus-Thermus and Actinobacteria, Bacteroidetes and Firmicutes, Actinobacteria and Firmicutes) were also found.

\section{Comparison of bacterial genera along the euphotic gradient}

A total of 26 genera were represented in the associated isolates. The distribution of bacterial genera varied considerably across the euphotic gradient. Samples from the $1 \%$ light penetration sampling point revealed the highest phylogenetic heterogeneity, with 21 genera identified. The following genera were restricted to only one part of the euphotic gradient: Providencia, Micrococcus, Herbaspirillum, Aquitalea, Pseudomonas, Rahnella, Paenibacillus (1\% light penetration); Kocuria, Deinococcus, Burkholderia, Curtobacterium and Williamsia (10\% light penetration); and Microbacterium and Brevibacillus (100\% light penetration). In contrast, the genera Arthrobacter, Staphylococcus, Bacillus and Rahnella were found scattered throughout the euphotic gradient.

To compare the phylogenetic compositions of the communities, we used UniFrac to statistically compare sequence sets representative of each community. We used the cluster environments function to 
compare the communities from each part of the euphotic gradient. Samples were clustered using UPGMA. The communities from each part of the gradient were on a completely different branch, and the $1 \%$ euphotic gradient community was more similar to the $100 \%$ euphotic gradient community than to the $10 \%$ euphotic gradient community. The robustness of this result was confirmed by jackknife analysis $(\mathrm{p}<$ 0.001). Bacterial communities retrieved from the tree points of the euphotic gradient were significantly different, as shown by UniFrac significance tests $(p \leq$ 0.05). In PCA analysis, the first principal component accounted for $65.13 \%$ of the variation in the data and clearly separated the $1 \%$ and $100 \%$ euphotic gradient communities from the bacterial community at $10 \%$ (Fig. 5). The highest similarity was between the $1 \%$ and $100 \%$ euphotic gradient communities.

\section{Detection of genomic variability between associated isolates}

We used interspersed repetitive sequence PCR to discern genetic relationships among isolates derived from the same original colony. Fingerprints generated by $(\mathrm{GTG})_{5}$-PCR were composed of 1 to 14 bands of varying sizes (300-5000 bp) and intensities. Fifty-five dendrograms (46 with 2 associated isolates, 7 with 3 associated isolates and 2 with 4 associated isolates) were generated from $(\mathrm{GTG})_{5}$ fingerprinting. Overall, the dendrograms revealed that no isolate presented $100 \%$ similarity with its associated isolates (Fig. 6).

\section{DISCUSSION}

The non-viability of some isolates after physical separation could be an indication of their physiological inability to survive and reproduce in the absence of certain associations. It is possible that the failure of some associated isolates (47/168) to grow in pure culture could be due to depletion of their endogenous reserves or even to an absence of minimum levels of certain metabolites in the PTYG medium.

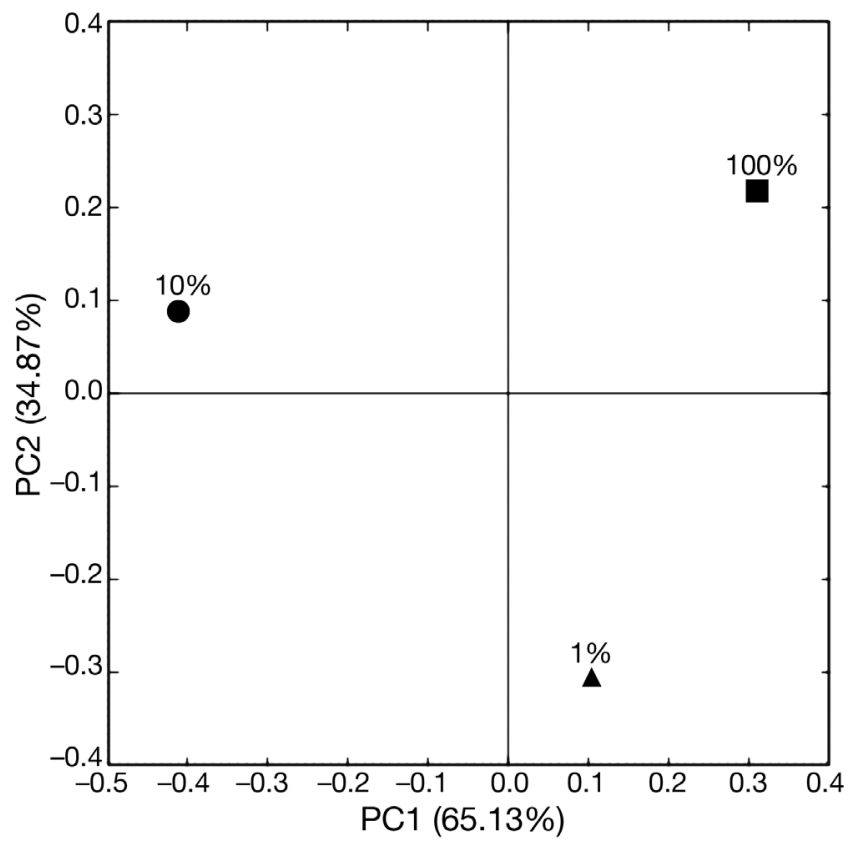

Fig. 5. Principal component (PC) analysis ordination plot for the 16S rRNA gene of associated isolates from bacterial colonies sampled at 1, 10 and $100 \%$ light penetration along a euphotic gradient. Percent variation explained by each $\mathrm{PC}$ is indicated on the axis labels

Most of the colonies harboring associated isolates and those that harbored the largest number of isolates were derived from the $1 \%$ light penetration sampling point. This result can be explained by the fact that light is essential in water environments. In a situation when light penetration levels are ideal, phytoplankton release their excess exudates (dissolved organic matter), which is the cornerstone of the food web (Pomeroy et al. 2007). These exudates are then used by heterotrophic bacteria for the maintenance of cell components, providing $50 \%$ or more of the bacterial total carbon demand (Sundh 1992). By contrast, heterotrophic bacteria liberate orthophosphate from organic phosphate, creating a symbiotic cycle (Pomeroy et al. 2007, Pringault et al. 2009). Alternatively, at $1 \%$ light penetration, the cycle is disturbed. The phytoplankton no longer produce exudates because the rate of photosynthesis is

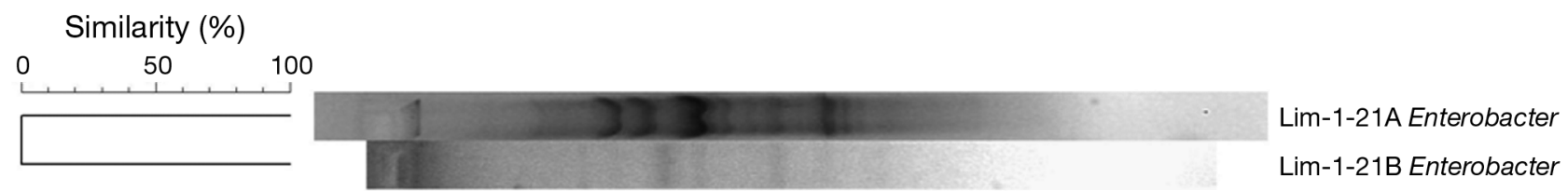

Fig. 6. Dendrogram showing the genetic relatedness among associated isolates as determined by (GTG) $)_{5}$-PCR fingerprint analysis. Similarity $(\%)$ between patterns was calculated using the Pearson coefficient, and data were sorted by UPGMA clustering. The colony shown is Lim1-21, which harbored associated isolates of Enterobacter 
low, and they consume everything they produce. Accordingly, those bacteria that live in a microbial loop interact with other bacteria as a strategy to seek other ways to obtain and exchange energy. According to Schink (2002) and Stams \& Plugge (2009), the formation of bacterial associations can facilitate the production of energy through the exchange of metabolites, and then the associations would be a way to save energy and survive in an inhospitable environment. Thus, the hypothesis of formation of bacterial associations in environments with disturbed microbial loop is supported by a negative correlation ( $p<0.05)$, observed in our study, between DO concentration and the largest number of isolates derived from a single colony.

Analysis of the V2 to V4 variable regions of the $16 \mathrm{~S}$ rRNA gene allowed us to make an accurate phylogenetic assignment of the associated isolates at the genus level. The phylogenetic tree created from $16 \mathrm{~S}$ rRNA gene sequences from associated isolates included several bacterial taxonomic groups. Five phyla were identified: Actinobacteria, Bacteroidetes, Firmicutes, Deinococcus-Thermus and Proteobacteria. This result is in agreement with previous studies of bacterial diversity in freshwater, which have reported the occurrence of these phyla (Hiorns et al. 1997, Berg et al. 2009). Moreover, the dominance of Proteobacteria and the relatively small numbers of Bacteroidetes and Deinococcus-Thermus have also been reported in previous studies (Lemke et al. 2009, Pontes et al. 2009). Enterobacter, Moraxella, Staphylococcus and Acinetobacter have also been detected in lentic environments (Berg et al. 2009, Lemke et al. 2009).

In this study, the UniFrac method was applied to distinguish the bacterial communities among euphotic gradients based on the phylogenetic analysis. PCA of UniFrac distances resulted in a clustering pattern at $1 \%$ and $100 \%$ light penetration, suggesting that despite differences in the number of the associated isolates in these euphotic gradients, the bacterial community structures are statistically similar.

In the present work, we selected isolates on the basis of colony morphotype in order to include distinct taxa derived from a single colony; however, this selection method may have imposed some bias because a single bacterial species can exhibit several distinct colony morphologies, and morphologically indistinguishable colonies can contain taxonomically different bacteria. Indeed, phylogenetic analysis of bacterial 16S rRNA gene fragments demonstrated that the re-streaking technique is an effective tool for separating taxa. Nevertheless, analysis of 16S rRNA gene sequences also indicated that some of the iso- lates, although representing different colony morphotypes, were phylogenetically related. For these reasons, the associated isolates in this study may represent a subset of a larger natural bacterial consortium. It should be pointed out that some isolates affiliated with the same species, although unable to grow after physical separation, were represented in our culture collection.

To best explore the genetic relationships between associated isolates, we performed (GTG) $)_{5}$-PCR fingerprinting. This genomic fingerprinting technique has been successfully used in several studies on the separation of non-clonal strains and can reveal intraspecific polymorphisms (Tindall et al. 2010). The results obtained from genomic fingerprinting revealed that associated isolates exhibiting identical 16S rDNA sequences exhibited genomic variability, indicating that these isolates are non-clonal. Therefore, the results indicate that the purification treatment was suitable to separate randomly stuck cells before streaking and to identify truly associated cells.

In conclusion, we have identified diverse taxa, including distinct phyla, among associated isolates derived from mixed colonies. Our genomic fingerprinting analysis indicates that phylogenetically distant bacteria coexist in natural environmental associations. In addition, environmental parameters appear to have important effects on the distribution and number of associations. Thus, the data obtained in the present study are very likely of ecological relevance, and now the challenge is to understand how these bacteria coexist.

Acknowledgements. We thank the Foundation for Research Support of the State of Minas Gerais (FAPEMIG), the Coordination for the Improvement of Higher Level — or Education Personnel (CAPES) and the National Council for Scientific and Technological Development (CNPq) for providing financial support. F.A.R.B. and A.M.A.N. were supported by CNPq.

\section{LITERATURE CITED}

Berg KA, Sivonen L, Paulin CKL, Suomalainen S, Tuomi P, Rapala J (2009) High diversity of cultivable heterotrophic bacteria in association with cyanobacterial water blooms. ISME J 3:314-325

Bezerra-Neto JF, Briguenti LS, Pinto-Coelho RM (2010) A new morphometric study of Carioca Lake, Parque Estadual do Rio Doce (PERD), Minas Gerais State, Brazil. Acta Sci Biol Sci 32:49-54

Bortoluzzi RLC, Carvalho-Okano RM, Garcia FCP, Tozzi AMGA (2004) Leguminosae, Papilionoideae no Parque Estadual do Rio Doce, Minas Gerais, Brasil. Acta Bot Bras 18:49-71

Brown MG, Balkwill DL (2009) Antibiotic resistance in bacteria isolated from the deep terrestrial subsurface. Microb Ecol 57:484-493 
Dramsi S, Biswas I, Maguin E, Braun L, Mastroeni P, Cossart P (1995) Entry of Listeria monocytogenes into hepatocytes requires expression of inIB, a surface protein of the internalin multigene family. Mol Microbiol 16:251-261

Ewing B, Green P (1998) Base-calling of automated sequencer traces using Phred II, error probabilities. Genome Res 8:186-194

Freitas DB, Lima-Bittencourt CI, Reis MP, Costa PS, Assis PS, Chartone-Souza E, Nascimento AMA (2008) Molecular characterization of early colonizer bacteria from wastes in a steel plant. Lett Appl Microbiol 47:241-249

Golterman HL, Clymo RS, Ohnstad MAM (1978) Methods for chemical analysis of fresh waters. Blackwell Scientific Publications, Philadelphia, PA

Gordon D, Abajian C, Green P (1998) Consed: a graphical tool for sequence finishing. Genome Res 8:195-202

> Häne BG, Jäger K, Drexler HG (1993) The Pearson productmoment correlation coefficient is better suited for identification of DNA fingerprint profiles than band matching algorithms. Electrophoresis 14:967-972

Hiorns WD, Methe BA, Nierzwicki-Bauer SA, Zehr JP (1997) Bacterial diversity in Adirondack mountain lakes as revealed by $16 \mathrm{~S}$ rRNA gene sequences. Appl Environ Microbiol 63:2957-2960

Kuske CR, Barns SM, Busch JD (1997) Diverse uncultivated bacterial groups from soils of the arid southwestern United States that are present in many geographic regions. Appl Environ Microbiol 63:3614-3621

Lemke MJ, Lienau EK, Rothe J, Pagioro TA, Rosenfeld J, Desalle R (2009) Description of freshwater bacterial assemblages from the upper Paraná river flood pulse system, Brazil. Microb Ecol 57:94-103

Little AE, Robinson CJ, Peterson SB, Raffa KF, Handelsman $\mathrm{J}$ (2008) Rules of engagement: interspecies interactions that regulate microbial communities. Annu Rev Microbiol 62:375-401

Lozupone C, Knight R (2005) UniFrac: a new phylogenetic method for comparing microbial communities. Appl Environ Microbiol 71:8228-8235

Lozupone C, Hamady M, Knight R (2006) UniFrac-an online tool for comparing microbial community diversity in a phylogenetic context. BMC Bioinformatics 7:371 doi:10.1186/1471-2105-7-371

Lu JJ, Perng CL, Lee SY, Wan CC (2000) Use of PCR with universal primers and restriction endonuclease digestions for detection and identification of common bacterial

Editorial responsibility: Hans-Georg Hoppe, Kiel, Germany pathogens in cerebrospinal fluid. J Clin Microbiol 38: 2076-2080

Mackereth FJH, Heron J, Talling JF (1978) Water analysis: some revised methods for limnologists. Freshwater Biological Association Scientific Publication, Wareham

Pomeroy LR, Williams PJI, Azam F, Hobbie JE (2007) The microbial loop. Oceanography 20:28-33

Pontes DS, Pinheiro FA, Lima-Bittencourt CI, Guedes RL and others (2009) Multiple antimicrobial resistance of gram-negative bacteria from natural oligotrophic lakes under distinct anthropogenic influence in a tropical region. Microb Ecol 58:762-772

Pringault O, Tesson S, Rochelle-Newall E (2009) Respiration in the light and bacterio-phytoplankton coupling in a coastal environment. Microb Ecol 57:321-334

Rudi K, Zimonja M, Trosvik P, Naes T (2007) Use of multivariate statistics for $16 \mathrm{~S}$ rRNA gene analysis of microbial communities. Int J Food Microbiol 120:95-99

Saitou N, Nei M (1987) The neighbor-joining method: a new method for reconstructing phylogenetic trees. Mol Biol Evol 4:406-425

Salas HJ, Martino P (1991) A simplified phosphorus trophic state model for warm-water tropical lakes. Water Res 25: 341-350

Schink B (2002) Synergistic interactions in the microbial world. Antonie Van Leeuwenhoek 81:257-261

Shapiro JA, Dworkin M (1997) Bacteria as multicellular organisms. Oxford University Press, New York, NY

Stams AJM, Plugge CM (2009) Electron transfer in syntrophic communities of anaerobic bacteria and archaea. Nat Rev Microbiol 7:568-577

> Sundh I (1992) Biochemical composition of dissolved organic carbon derived from phytoplankton and used by heterotrophic bacteria. Appl Environ Microbiol 58: 2938-2947

Tamura K, Dudley J, Nei M, Kumar S (2007) MEGA4: molecular evolutionary genetics analysis (MEGA) software version 4.0. Mol Biol Evol 24:1596-1599

Tindall BJ, Rossello-Mora R, Busse HJ, Ludwig W, Kampfer $P$ (2010) Notes on the characterization of prokaryote strains for taxonomic purposes. Int J Syst Evol Microbiol 60:249-266

- Watanabe K, Kodama Y, Harayama S (2001) Design and evaluation of PCR primers to amplify 16S ribosomal DNA fragments used for community fingerprinting. J Microbiol Methods 44:253-262

Submitted: July 29, 2011; Accepted: February 13, 2012 Proofs received from author(s): March 22, 2012 